\title{
Parasitic plants of the genus Cuscuta and their interaction with susceptible and resistant host plants
}

\author{
Bettina Kaiser ${ }^{1}$, Gerd Vogg ${ }^{2}$, Ursula B. Fürst ${ }^{1}$ and Markus Albert ${ }^{1}$ * \\ ${ }^{1}$ Institute of Plant Biochemistry, Centre for Plant Molecular Biology, University of Tübingen, Tübingen, Germany \\ 2 Department of Botany II - Ecophysiology and Vegetation Ecology, Julius-von-Sachs-Institut für Biowissenschaften, Botanischer Garten der Universität \\ Würzburg, University of Würzburg, Würzburg, Germany
}

\section{Edited by:}

Benjamin Schwessinger, University of California, Davis, USA

Reviewed by:

James H. Westwood, Virginia Polytechnic Institute and State University, USA

Moran Farhi, University of California, Davis, USA

\section{${ }^{*}$ Correspondence:}

Markus Albert, Institute of Plant Biochemistry, Centre for Plant

Molecular Biology, University of Tübingen, Auf der Morgenstelle 32,

72076 Tübingen, Germany

e-mail:markus.albert@zmbp.

uni-tuebingen.de
By comparison with plant-microbe interaction, little is known about the interaction of parasitic plants with their hosts. Plants of the genus Cuscuta belong to the family of Cuscutaceae and comprise about 200 species, all of which live as stem holoparasites on other plants. Cuscuta spp. possess no roots nor fully expanded leaves and the vegetative portion appears to be a stem only. The parasite winds around plants and penetrates the host stems via haustoria, forming direct connections to the vascular bundles of their hosts to withdraw water, carbohydrates, and other solutes. Besides susceptible hosts, a few plants exist that exhibit an active resistance against infestation by Cuscuta spp. For example, cultivated tomato (Solanum lycopersicum) fends off Cuscuta reflexa by means of a hypersensitive-type response occurring in the early penetration phase. This report on the plant-plant dialog between Cuscuta spp. and its host plants focuses on the incompatible interaction of $C$. reflexa with tomato.

Keywords: parasitic plants, plant-plant interaction, Cuscuta, dodder, plant immunity, resistance, symbiosis

\section{INTRODUCTION}

Plants live in a world populated by numerous and varied herbivores and microbial pathogens that include insects, nematodes fungi, bacteria, and oomycetes. However, plants have evolved mechanisms to detect such attacks and counteract them with efficient immune responses. Much of our knowledge about pathogen recognition of plants originates from studies of plantmicrobe or plant-insect/herbivore interactions, in which plant immunoreceptors detect specific microbe-associated molecular patterns (MAMPs) that are often highly conserved microbial structures, such as bacterial flagellin or fungal chitin. Activation of these immunoreceptors, also termed pattern recognition receptors (PRR), triggers a set of typical defense responses that include rapid production of reactive oxygen species (ROS-burst), elevation of the stress-related phytohormone ethylene, increased levels of secondary metabolites (callose, phytoalexins, lignins, etc.) and the induction of characteristic marker genes (Boller and Felix, 2009; Böhm et al., 2014). Additionally, plant defense responses include signaling via networks controlled by the phytohormones salicylic acid (SA) and jasmonic acid (JA; Dong, 1998; Wasternack et al., 2006). In particular, SA is required for the initiation of a hypersensitive response (HR) and to trigger systemic acquired resistance (SAR; Durrant and Dong, 2004). Taken together, plants present a complex network of defense reactions to fend off pathogens or at least to restrict the pathogen growth and spread.

Apart from microbial pathogens and herbivorous arthropods, plants are also parasitized by other plants. Parasitic plants feed on their hosts (from the Greek para = beside; sitos = food) and keep them alive until they have completed their life cycle. Most often the parasite's life cycle is completed earlier than the one of the host plant which leads to a premature death of the parasitized plants and thus can cause crop damage. Parasitic plants are categorized as either obligate or facultative parasites, depending on whether they rely totally on their hosts to complete their life cycle (obligate) or are able to survive on their own in the absence of their host plants (facultative). Additionally, parasitic plants can be divided into hemiparasites that rely only partially on a host plant and are still able to make photosynthesis and holoparasites that are completely dependent on photoassimilates, solutes, and metabolites from their host plants. According to their preferred target host organ, parasitic plants are defined as either root or shoot parasites.

Here, we describe the parasitic plant Cuscuta spp.-also known as dodder - which can be defined as an obligate stem holoparasite. Besides describing its life style and mechanisms for infecting susceptible host plants, we will focus on Cuscuta spp. as pathogens. Using mainly tomato vs. Cuscuta reflexa as an example, resistance mechanisms of plants against plant parasites will be illustrated and discussed, highlighting future prospects of controlling Cuscuta infestations during crop cultivation.

\section{Cuscuta ssp. - OCCURRENCE AND AGRONOMICAL ROLE}

Among the flowering plants, there are approximately 3,900 known parasitic plant species in more than 20 plant families (Westwood et al., 2010). Well-known and agriculturally important genera include Striga and Orobanche from the Orobanchaceae family and Cuscuta spp. (Figure 1) from the family of Convolvulaceae. While Striga and Orobanche can severely affect crop yields in drier and warmer areas of Africa and Asia (Spallek et al., 2013), Cuscuta spp. thrive in regions with a warm and more humid climate where the highest Cuscuta-dependent crop yield losses also occur (Dawson et al., 1994). Nevertheless, Cuscuta species can be found on all continents; for example, five species are native 


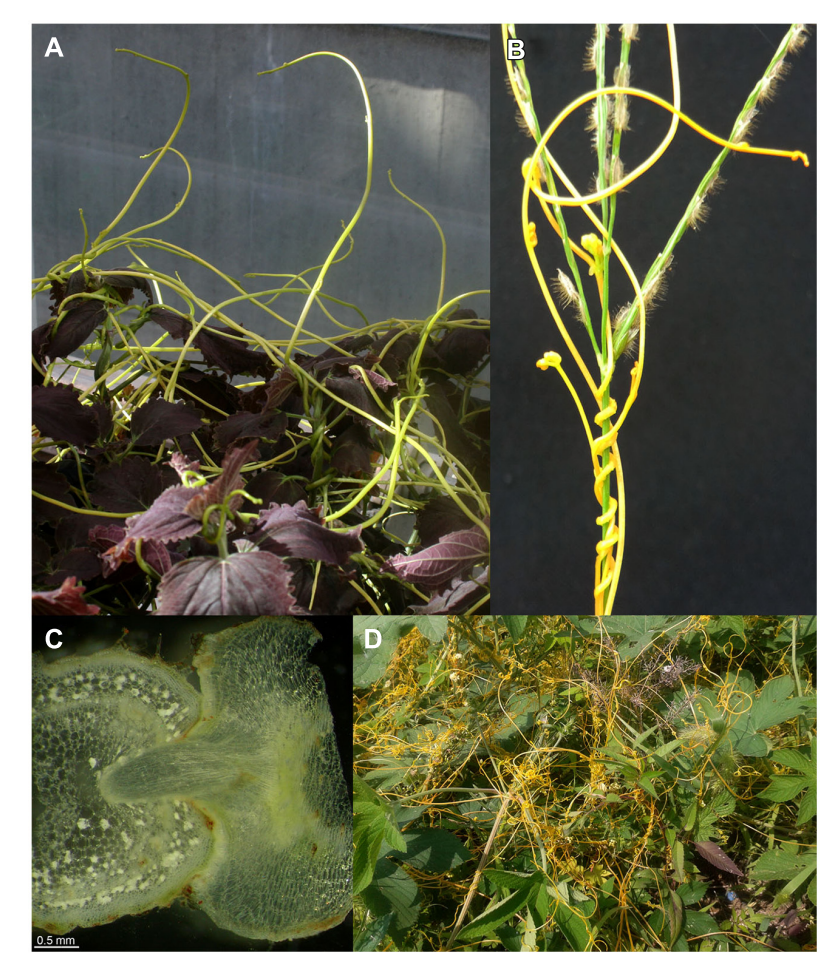

FIGURE 1 | Cuscuta spp. on susceptible host plants. (A) Cuscuta reflexa on Coleus blumei; cultivation in the greenhouse, University of Tübingen. (B,D) Cuscuta australis near Daejin-University, Pocheon, South Korea. (B) C. australis infecting a grass (monocotyledon). (C) Cross section of a $C$. reflexa haustorium growing into the shoot of a susceptible host plant (Nicotiana benthamiana) (D) C. australis on a dicotyledonous host plant.

to central Europe (Mabberley, 1997), of which C. europaea is the most prominent. Agriculturally, the most important Cuscuta species are C. pentagona and C. campestris, which show an almost worldwide distribution and have a wide host spectrum. Severe crop loss due to Cuscuta is reported for 25 crop species in 55 countries (Lanini and Kogan, 2005). Highest species diversity for dodder occurs in the Americas, from Canada to Chile (Yuncker, 1932; Stefanovic et al., 2007). In Chilean crops, C. chilensis, C. racemosa var. chiliana, and $C$. pentagona are important. The biogeography of Cuscuta has recently been studied using plastid protein-coding $(r b c L)$ and nuclear large-subunit ribosomal DNA ( $n r L S U$ ) sequences covering the morphological, physiological, and geographical diversity of the genus (Garcia et al., 2014). This work supports the classical subgenera Monogynella and Grammica as monophyletic, leaving a paraphyletic subgenus Cuscuta, with the section Pachystigma as sister to the section Grammica. However, as Cuscuta is the only parasitic genus in the Convolvulaceae family, there is high similarity among the species within this genus (Garcia et al., 2014).

\section{Cuscuta LIFE CYCLE}

Parasitic plants of the genus Cuscuta have no chlorophyll, or only a reduced amount, and are not usually photosynthetically active (Kuijt, 1969; Hibberd et al., 1998; Garcia et al., 2014). Only a few Cuscuta species still show residual photosynthesis (Dawson et al.,
1994; Hibberd et al., 1998) and have thus been designated as cryptically photosynthetic (Funk et al., 2007; McNeal et al., 2007a,b). However, all Cuscuta species depend (absolutely) on a host plant to complete their life cycle, and Cuscuta can be considered an obligate holoparasite.

Like other angiosperms, the life cycle of Cuscuta begins with seed germination. Germinating Cuscuta seedlings depend on limited seed reserves; they are unable to survive alone for a longer time and must find an appropriate host plant stem within the first few days. To find and catch potential hosts, Cuscuta recognizes plant volatiles as chemo-attractants which guide seedling growth and increase the chances of successful infection (Runyon et al., 2006). In the presented study, the authors worked with Cuscuta pentagona seedlings and tomato plants as hosts. A detailed analysis identified the volatile terpenoids $\alpha$-pinene, $\beta$-myrcene, and $\beta$-phellandrene as chemical cues that are produced by the tomato and serve as chemo-attractants for Cuscuta. As confirmed by our own observations of $C$. reflexa, the parasite does not distinguish between plant stems and sticks consisting of wood, metal, or plastic. The parasite winds around, totally unimpressed, and even develops (pre-) haustoria and tries to penetrate these victim-dummies. However, this was observed only with $C$. reflexa shoot parts taken from adult plants and not with C. reflexa seedlings. Runyon et al. (2010), in turn, used only $C$. pentagona seedlings, and could see no directed seedling growth to control stems such as artificial plants or vials of colored water (Mescher et al., 2006). In general, both detection of eventual light and chemical cues would require highly sensitive perceptual systems in Cuscuta ssp., but to date no such systems or receptors have been identified.

After finding an appropriate host plant, the first physical contact initiates an attachment phase, in which the parasitic epidermal and parenchymal cells begin to differentiate into a secondary meristem and develop prehaustoria, also known as adhesive disk (Dörr, 1968; Heidejorgensen, 1991). Important signals initiating and controlling this prehaustoria formation include mechanical pressure, osmotic potentials, and phytohormones such as cytokinins and auxin (Dawson et al., 1994; Runyon et al., 2010). The prehaustorial cells start to produce and secrete adhesive substances such as pectins and other polysaccharides, reinforcing the adhesion (Vaughn, 2002). During this attachment phase, host cells in proximity to the Cuscuta haustoria respond with an increase in cytosolic calcium, detectable in host plants expressing aequorin as calcium reporter. This increase lasts for about $48 \mathrm{~h}$ after the initial contact (Albert et al., 2010a,b). Cytosolic calcium signals are part of several signal transduction pathways, initiated by diverse stimuli such as touch, osmotic signals, phytohormones, or defense triggers. Since these signals could all be part of the plant-plant interaction, it is difficult as yet to assign a clear role for the described calcium spikes. Within the first hours of contact, Cuscuta also induces the host plant to produce its own sticky substances, such as arabinogalactan proteins, to promote adhesion (Albert et al., 2006). These glycoproteins are secreted by the host plant and localize to the cell-wall where they can force the adhesion together with other sticky components such as pectins. However, the initial signals from the parasite that trigger cellular responses in the hosts to mediate adhesion or consequent susceptibility are as yet unknown. 
The attachment phase is followed by the penetration phase as prehaustoria develop into parasitic haustoria that penetrate the host stem through a fissure. This breach is effected by mechanical pressure (Dawson et al., 1994) and is supported by the biochemical degradation of host cell walls, caused by secreted hydrolytic enzymes such as methylesterases (Srivastava et al., 1994) or complexes of lytic enzymes consisting of pectinases and cellulases (so-called "loosening particles"; Vaughn, 2003). Cells at the tip of the invading haustoria (Figure 1C) form "searching hyphae," which try to reach phloem or xylem cells of the host plant's vascular bundles. After contact with a sieve cell, the searching hyphae grow around the cell like the fingers of a hand, and the parasitic cell surface interacting with the host sieve cell is enlarged more than 20 times. These parasitic cells have been described as having ambivalent characters, functioning as both sieve elements and transfer cells (Dörr, 1968, 1969, 1972; Dawson et al., 1994). Interestingly, during this process, chimeric cell walls of host and parasite constituents are formed, and interspecific plasmodesmata build up a cytoplasmic syncytium between Cuscuta and the host plant (Haupt et al., 2001; Vaughn, 2003; Birschwilks et al., 2006). To form a connection to the xylem, parasitic and host cells of the xylem parenchyma commence a synchronized development, fusing to build a continuous xylem tube from the host to the parasite (Dörr, 1972). With functional connections to the xylem and phloem of its host, the parasitic plant is supplied with water, nutrients, and carbohydrates (Jeschke et al., 1994, 1997; Hibberd et al., 1999; Hibberd and Jeschke, 2001).

The haustorium (from Latin "haurire" = to drink) is the defining feature of all parasitic plants, representing the interface where nutrients, solutes, and carbohydrates are exchanged between host and parasite (Chang and Lynn, 1986; Dawson et al., 1994; Hibberd et al., 1999; Yoshida and Shirasu, 2009; Westwood et al., 2010). This interface also allows the exchange of macromolecules between the host plant and the parasite. For example, it has been demonstrated that phloem-mobile GFP, a $25 \mathrm{kDa}$ protein, can be successfully transferred from the host plant to Cuscuta (Haupt et al., 2001), probably by passing through the interspecific plasmodesmata. The transfer of viruses between parasite and host had already been described in 1947 (Sakimura, 1947); more recent publications report findings about the uptake of host RNAs by the parasite (Roney et al., 2007; David-Schwartz et al., 2008; Westwood et al., 2009). This phenomenon was also used in a biotechnological approach to cross-species transfer of small RNAs for the control of crop parasites (Runo et al., 2011) —specifically, of Cuscuta infestation (Alakonya et al., 2012)_and will be discussed in detail later. Very recently, it was shown that transcripts are transferred in a bidirectional manner between $C$. pentagona and susceptible host plants (Kim et al., 2014). In the presented study, the authors infected stems of tomato (Solanum lycopersicum) and Arabidopsis thaliana with $C$. pentagona, and isolated and sequenced RNA from the infection site, the host stem above the region of attachment and the parasite stem near the region of attachment. While it was expected that RNAs would move from the host into the parasite, the efficiency of this process was indeed surprising; almost half of the A. thaliana transcriptome was detectable in C. pentagona stem sections close to the haustoria. It was also astonishing that transcripts did not move only unidirectionally from host to parasite, but that parasitic transcripts were found in the host stems, just a few centimeters away from the infection site. The role of this bidirectional transcript exchange between plants is wholly unclear; one could speculate whether RNAs (especially small RNAs) might have a signaling function in hosts or parasites. It remains to be shown whether this interchange of RNAs has anything to do with horizontal gene transfer; a Cuscuta genome sequencing project would shed more light on such mechanisms. However, the impressive extent of exchanged macromolecules such as RNAs confirms the haustorium as an "open door" between host and parasite that seems not especially guarded.

\section{INTERACTION OF Cuscuta spp. WITH RESISTANT HOSTS}

Cuscuta spp. have a broad host spectrum and therefore lots of possible plant "victims" to sustain them, but there are a few plants that successfully fend off Cuscuta. Many Cuscuta species are not able to infect monocotyledonous plants, probably for anatomical reasons such as the arrangement of vascular bundles or incompatibility of signals that are important for forming interspecies connections of vascular strands (Dawson et al., 1994). Nevertheless, this incompatibility seems quite passive and exceptions exist-Cuscuta australis, for instance, is able to infect monocotyledonous plants (Figure 1B).

So, are there plants that can specifically detect and "actively" defend themselves against parasitic dodder? Examples of plants that appear to mount an active defense against Cuscuta include Malvaceae Gossypium hirsutum and Hibiscus rosa-sinensis, neither of which can be penetrated by Cuscuta spp. In these plants, connection of parasitic haustoria or searching hyphae to the host vascular bundles is blocked by a kind of wound tissue, and the parasitic cells of the searching hyphae-and finally the parasite-die off (Capderon et al., 1985).

Signs of an active resistance reaction can also be observed during the interaction of $C$. reflexa with the cultivated tomato (S. lycopersicum; Ihl etal., 1988; Albert et al., 2004, 2006; Runyon et al., 2010); at the end of the attachment phase, about 3-5 days after the parasitic prehaustoria have formed, epidermal host cells at the contact sites elongate strongly and burst (Ihl et al., 1988; Sahm et al., 1995; Löffler et al., 1999; Werner et al., 2001; Albert et al., 2004). This expansion of cells requires the expression of genes encoding proteins known to be involved in cell elongation, such as aquaporins (Werner et al., 2001) or proteins important for cell-wall modifications and restructuring like Xyloglucan endotransglycosylases/hydrolases (LeXTH; Albert et al., 2004). Cell elongation and gene expression are controlled by auxin, which strongly increases in the parasitic prehaustorium and in the epidermal tomato cells (Löffler et al., 1999). At the contact sites, tomato cells of the hypodermal tissue also elongate, and parenchymal cortex cells show increased cell division, resembling an extra meristem (Ihl et al., 1988). However, these responses are reminiscent of plant developmental processes rather than typical resistance responses. In particular, the involvement of an XTH, the expression of aquaporins and the growth-related phytohormone auxin indicate a developmental program that is probably also important for the infection of susceptible hosts. However, in parallel, C. reflexa appears to induce a defense program in the tomato, in which tomato cells at the infection site 
secrete soluble phenylpropanoids and show an increased accumulation and activity of peroxidases-enzymes that are important for linking phenylpropanoids with other components of the cell wall such as proteins, pectins, or cellulose fibers (Löffler et al., 1995, 1997; Sahm et al., 1995). This modified cell wall is thought to seal the infection site, preventing penetration of the tomato by $C$. reflexa. At the contact sites of $C$. reflexa haustoria with the tomato stem, a browning of tomato tissue, clearly visible by eye, appears within 5-7 days of interaction (Figure 2). Under UV light, this brownish tissue fluoresces strongly in a manner that indicates occurrence of phenylpropanoids in lignified plant tissues. When further analyzed for chemical composition by gas chromatography followed by mass spectrometry (GC-MS), this modified tissue, much like wound tissue, was indeed found to contain substances belonging to the phenylpropanoids (such as dihydroxycinnamic acid derivatives) as previously described (Löffler et al., 1995, 1997; Sahm et al., 1995), as well as long-chain (C18-C26) fatty acids (FA), $\omega$-OH-FAs, $\alpha-\omega$-dioic acids and primary alcohols (Figure 3; Albert, 2005). Together with the phenylpropanoids, these hydrophobic long-chain components are known to become cross-linked within the cell wall, building the "wound suberin" of the secondarily modified plant cell wall (Bernards, 2002; Leide et al., 2012).

In summary, in direct contact with $C$. reflexa haustoria, epidermal tomato cells elongate and die following a hypersensitive-type response (Ihl et al., 1988) while a secondarily modified tissue is formed in the hypodermis to protect against haustoria penetration. Finally, the parasite dies off about 14 days after first contact (Figure 2C).

Is this resistance to Cuscuta due only to a wound response? This is called into doubt by the observation that these wound symptoms, and induction of the two stress hormones SA and JA, also occur in the tomato after interaction with Cuscuta pentagona, which can successfully infect this host. C. pentagona, however, induces visible HR symptoms in tomato as well and can grow better on transgenic tomato plants expressing a gene for a salicylate hydroxylase $(n a h G)$. In these $n a h G$ plants, the HR symptoms



FIGURE 2 | Cuscuta reflexa on its resistant host plant Solanum lycopersicum (cultivated tomato). (A) C. reflexa $\sim 7$ days after initial contact to the tomato shoot. (B) Enlarged detail of (A) shows the secondarily modified tissue of tomato at the penetration sites next to the parasitic haustoria. (C) $C$. reflexa dies off $\sim 14$ days after initial contact with tomato; the secondarily modified tissue of tomato reminds of a kind of 'hypersensitive response' (HR). during the interaction with $C$. pentagona seem clearly reduced, indicating a correlation of SA level and HR symptoms during a Cuscuta attack (Runyon etal., 2010). Thus, a resistance mechanism including a host wound response or not, might be the sum of several factors and might depend on a threshold of the strength of diverse host defense responses that has to be passed for winning this battle (Figure 4). Indeed, the strong resistance reaction of cultivated tomato ( $S$. lycopersicum) seems very specific to C. reflexa; several other Cuscuta species can successfully infect tomato, including C. pentagona, C. suaveolens, and C. europaea (Jiang et al., 2013b; Ranjan et al., 2014). In addition, wound responses at infection sites are not restricted to S. lycopersicum but also occur in nearly all host plants, so that wounding may not be sufficient to account for the complete resistance observed in the C. reflexa-S. lycopersicum interaction. Also possible, dodder might actively block wound and defense responses when infecting susceptible plants by suppressors and an unsuccessful suppression of these responses could lead to defense or resistance as well (Figure 4).

The resistance reactions of tomato to C. reflexa attack may go beyond wound responses to include other reactions that are commonly observed after infection by microbial pathogens (Figure 4). Plant hosts can detect microbial pathogens in different ways, either directly by perception of MAMPs or indirectly by perception of damage-associated molecular patterns (DAMPs) that arise during attack by pathogens. DAMPs comprise a range of different molecules, from solubilized fragments of cell-walls or plasma membrane constituents to cytoplasmic proteins and ATP (Küfner etal., 2009; Ottmann etal., 2009; Bartels etal., 2013; Choi et al., 2014). DAMPs and MAMPs both signal "danger" to the host plant, and both types of signal are generally perceived via receptor proteins at the surface of the plant cells (Dodds and Rathjen, 2010; Böhm et al., 2014; Macho and Zipfel, 2014). In addition, plants have further systems for pathogen detection that function mainly intracellularly and depend on an array of resistance proteins (Lanfermeijer et al., 2003). Typically, these resistance proteins trigger strong HR-symptoms which look cortically similar to those induced by $C$. reflexa on a tomato stem and thus could provide a comparable mechanism for the observed resistance. Together with membrane bound receptors (e.g., LRR-RLPs), the intracellular NBS-LRR proteins are known to recognize pathogen-derived avirulence (avr) proteins. Famous examples therefore identified in tomato might be presented by Cf-receptor proteins and their recognized AVR-protein ligands, encoded by the avr-genes of the fungus Cladosporium fulvum (Cf; De Wit etal., 2009; Wulff etal., 2009). The perception of AVR4 by its cognate receptor Cf- 4 follows the concept of a gene-for-gene interaction and already a single point mutation in the avr-gene leads to a mismatch and consequently to a lack of resistance (Joosten et al., 1994). This gene-for-gene model has already been observed and defined earlier (Flor, 1956, 1971) and has been used in breeding efforts to select pathogen-resistant genotypes of single plant species for a very long time.

About 10 years ago, this strategy was also applied to screen different commercial hybrid tomato varieties for their resistance responses to lespedeza dodder. In this study, three varieties have 


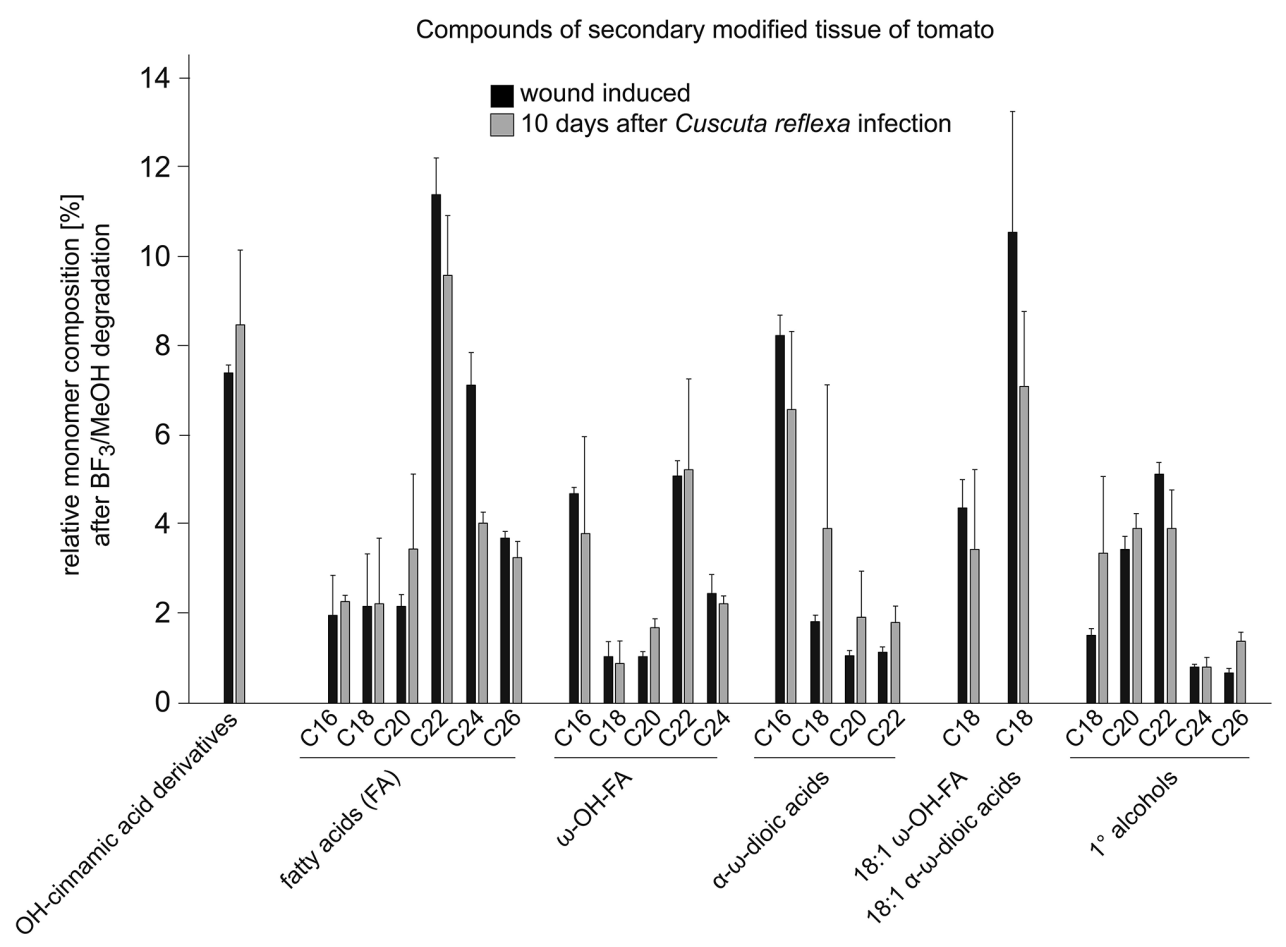

FIGURE 3 | Relative monomer composition of the secondarily modified tomato tissue. The constituents were isolated from tomato shoot tissue infected with $C$. reflexa for $\sim 10$ days (for example see Figure $\mathbf{2 C}$ ). Tissue was treated and degraded by $\mathrm{BF}_{3}$-methanolysis as described (Supplementary information, Leide etal., 2012) and analyzed via gas chromatography followed by mass spectrometry. Results (gray bars) were compared to those obtained after similar treatment of 'wounding tissue' (black bars; tomato stem

$\sim 10$ days post wounding). Values are given in \% of total constituents and represent means of measurements from three independent samples; error bars indicate SD. been identified which exhibited tolerance (resistance) to the parasite compared to the fully susceptible variety "Halley 3155 ." The resistance against this dodder species seems to be incomplete since the dodder haustoria still could penetrate the tomato stem in many cases. However, in field studies, 75\% less lespedeza dodder attachments were observed on tolerant varieties, and dodder growth was reduced by more than 70\% (Goldwasser, 2001). The highly variable resistance of tomatoes which seems to appear at various strengths argues for a phenomenon driven by quantitative resistant traits. Supposably, resistance genes, or their encoded proteins, respectively, act synergistically to display a full resistance. As soon as one component lacks, resistance symptoms might be visible on tomato stems without committing full resistance.

Within other plant genera genotypes resistant against Cuscuta spp. were identified as well. After a large-scale greenhouse experiment, a set of chickpea genotypes (Cicer arietinum) was screened for the resistance response to Cuscuta campestris (Goldwasser et al., 2012). While most of the chickpea varieties displayed susceptibility, two genotypes were identified which clearly showed resistance against C. campestris and $80 \%$ of these chickpea plants were fully resistant. This resistance mechanism, however, seems to be different from the one observed for tomato plants since it lacks a HR-like response or lignification close to the haustoria attachment sites. The phenomenon was described as a kind of passive repellent of the parasite haustorium prior to penetration and consequently starvation of C. campestris (Goldwasser et al., 2012).
Similar resistance mechanisms of haustoria penetration rejection have been reported for crops against root parasites of the Orobanche spp. (Goldwasser et al., 2000; Perez-de-Luque et al., 2006, 2008; Yoder and Scholes, 2010). For example, in chickpea lines resistant against Orobanche crenata Forsk., the ingrowth of haustoria was blocked before reaching the central cylinder of the host roots (Rubiales et al., 2003). The resistance response of cowpea cultivar B301 to race 3 (SG3) of Striga gesnerioides is characterized by an inability of the parasite to penetrate the endodermis and by necrosis of the host tissue at the point of attachment as well. In 2009, a gene conferring this resistance against Striga was identified in cowpea which encodes for an intracellular resistance protein of the CC-NBS-LRR family (Li and Timko, 2009). Since the resistance of diverse cowpea cultivars against different Striga species is race specific, the resistance mechanism clearly follows a gene-for-gene interaction model (Li and Timko, 2009; Li et al., 2009). Although root-parasites of the Orobanchaceae infect an anatomically different organ than shoot parasites of the genera Cuscuta, the cellular resistance mechanisms might show parallels. A few inspiring works were reviewed by Yoder and Scholes (2010).

At present it is not clear whether resistance of tomato to $C$. reflexa depends on one or more specific resistance proteins. It is also unclear as yet whether C. reflexa produces DAMPs or whether it releases molecular patterns that are perceived by tomato in a manner analogous to MAMPs or avr proteins. However, such mechanisms are imaginable and the question of how C. reflexa 


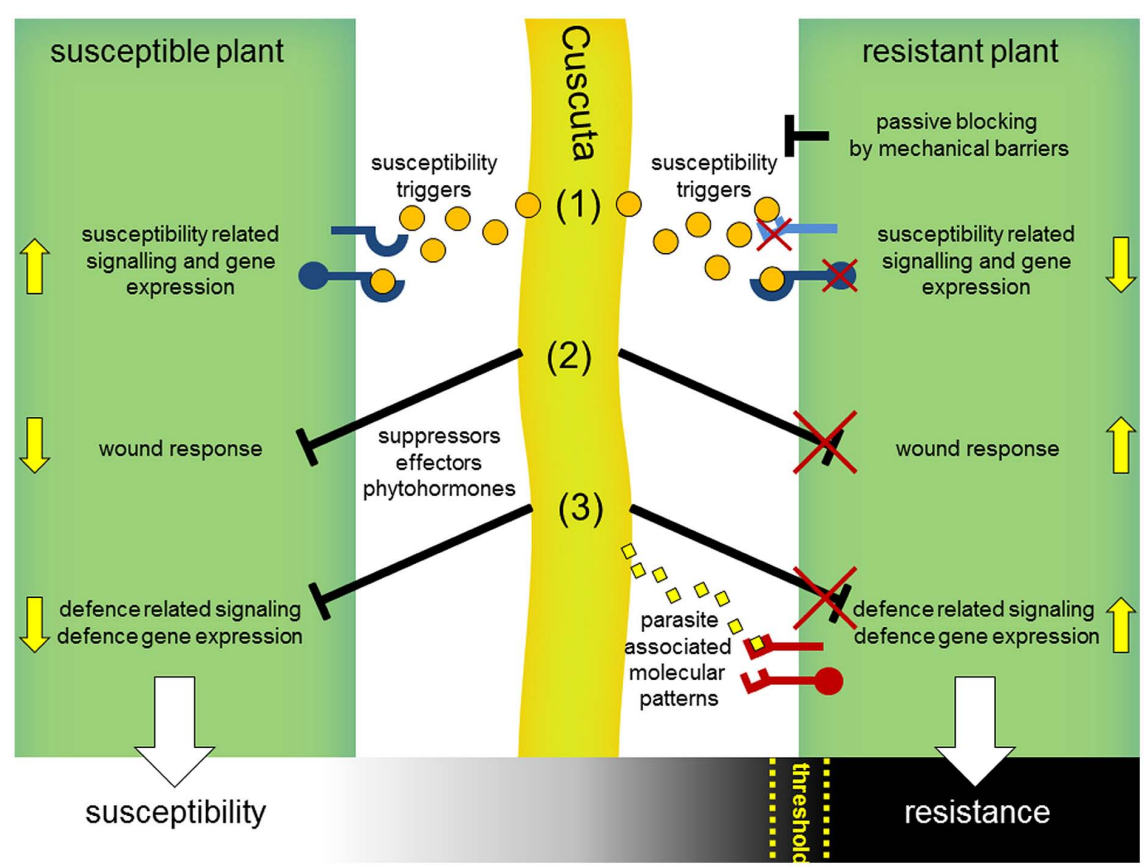

FIGURE 4 | Hypothetical model for interaction mechanisms of parasitic Cuscuta with susceptible and resistant host plants. Cuscuta (middle, light green) attacking susceptible plants (left) release susceptibility triggers (orange dots) including common phytohormones and yet unknown signals, which get perceived by host plant receptors (blue) and consequently manipulate hosts to set on susceptibility-related responses and gene expression (1). In parallel, wound-related (2) and defense-related responses (3) that occur in the context of host penetration might get blocked by yet unknown suppressors. Resistant plants (right) might prevent a parasitic attack passively, e.g., by reinforced cell walls as mechanical barriers or by non-responsiveness to susceptibility triggers (1).
Incompatibility could also result from a deficient blocking of the host wound (2) or defense response (3). In analogy to the perception of microbial pathogens, defense reactions might be actively triggered by host immunoreceptors (PRRs, red) that detect specific parasite-associated molecular patterns (3) (yellow diamonds) or secondary generated (e.g., by parasitic hydrolytic enzymes) damage-associated molecular patterns (DAMPs). Susceptibility or resistance of host plants might be a sum of these interaction processes and, rather than black and white, appears to be a gradual process occurring in many plants. Thus, a certain threshold for the strength of defense reactions might be passed by host plants for a successful resistance against dodder. is perceived by the tomato immune system is one of the topics currently under investigation in our lab.

\section{CONTROLLING Cuscuta spp. INFECTIONS}

Cuscuta spp. has a wide host range, including many cultivated crops such as tomato, tobacco, clover, and dicotyledonous weeds as well as trees and shrubs, but only a few grasses or monocotyledonous weeds (Dawson et al., 1994; Albert et al., 2008). Hosts are attacked non-specifically and sometimes even simultaneously, and one crop species may serve as a host for several dodder species (Cudney and Lanini, 2000). Depending on the infected plant species, Cuscuta infestation has more or less severe effects on the growth and reproduction of its host. Rather than causing host death, Cuscuta infestation seems to weaken host plants and to render them more susceptible to secondary diseases such as infection by microbes or insect and nematode infestation (Lanini and Kogan, 2005).

Dodder seeds are easily spread by animals and man, notably through international exchange of contaminated host seeds or movement of equipment or soil (Cudney and Lanini, 2000). Once established in a field, it can be problematic to get rid of Cuscuta. Preventive measures such as crop rotation with non-host plants, delaying planting until fall, use of resistant varieties and use of herbicides are effective only to an extent (Parker, 1991); once Cuscuta is attached to its host, containment becomes difficult (Lanini and Kogan, 2005). The use of genetically modified, herbicide-resistant crops has been tested but has proved unpromising (Nadler-Hassar and Rubin, 2003). The protein PAT (phosphinothricin acetyl transferase), which confers resistance to the herbicide glufosinate, has been shown to traffic between herbicide tolerant soybeans and Cuscuta pentagona and is therefore not an option for controlling dodder (Jiang et al., 2013a). As none of the described strategies is 100\% effective, and given the invasion by new Cuscuta speciese.g., C. reflexa (giant dodder), as introduced in California and New Zealand (Rejmanek and Pitcairn, 2002)_further research is required.

Promising future strategies for the control of parasitic plant infestations include transgenic plants expressing specifically designed small RNAs (Roney et al., 2007; Runo et al., 2011, 2012; Alakonya et al., 2012). This biotechnological approach of crossspecies transfer of small RNAs has been shown to work well for control of Cuscuta infestations. Transgenic host plants expressing phloem-specific RNAi-constructs for SHOOT MERISTEMLESSlike (STM), a protein that plays an essential role in parasitic haustoria development, were infected with Cuscuta pentagona. 
The small RNAs successfully moved from the host into the C. pentagona haustoria, where they interfered with haustoria growth and consequently inhibited haustorium development, so reducing the infection (Alakonya et al., 2012). Further useful and promising strategies might include the control of parasitic enzymes essential for the Cuscuta infection process, such as blocking the infestation-specific cysteine protease Cuscutain by external application of its intrinsic inhibitor peptide in high excess (Bleischwitz etal., 2010). While promising, these approaches require improvement and optimization to reach the standards of agronomical application. Additionally, screening for resistant genotypes of certain crop species as described (Goldwasser, 2001; Goldwasser et al., 2012), breeding of resistant varieties and the transfer of resistance genes from one species (e.g., tomato) to crop plants may offer further means of controlling Cuscuta infection.

\section{CONCLUSION AND PERSPECTIVES}

To establish strategies to control parasite growth and restrict the spread of Cuscuta spp. in crop fields, it is important to learn more about this pest, studying its life cycle, its development, and its molecular mechanisms of infection. Using a next-generation RNA sequencing platform, two very recent articles have focused on expressed genes of Cuscuta during the infection process as well as in growth and development (Jiang et al., 2013b; Ranjan et al., 2014). Jiang et al. (2013b) focused on two Cuscuta species, C. pentagona and C. suaveolens, and were able to provide more than 46,000 isotigs and contigs for each species. Interestingly, after comparing the datasets with sequencelibraries of other parasitic plants such as Triphysaria, Orobanche, and Striga, they could identify a set of ESTs that seem to be shared exclusively by parasitic plants. Ranjan et al. (2014) isolated RNAs of Cuscuta pentagona at different stages (i.e., from seeds, seedlings, vegetative strands, prehaustoria, haustoria, and flowers) and used them for de novo assembly and transcriptome annotation. These transcript pools provided insights into the transcriptional dynamics during dodder development as well as parasitism, and helped to identify gene categories involved in the infection processes of diverse stages (Ranjan et al., 2014). The use of these modern sequencing methods offers an overview and could nicely correlate the expression of certain genes during certain phases and processes in the life cycle of Cuscuta. However, these pioneering studies must be broadened through detailed analyses of molecular mechanisms, and further comprehensive studies of individual genes and their proteins will be necessary in order to understand the molecular mechanisms of infection processes. In particular, the identification of genes or proteins with key functions in mediating susceptibility or resistance to Cuscuta infestation will be of great importance. For example, identification of the receptors that perceive parasitic signals and initiate a "susceptibility" program in the host plants, as well as the signals secreted by the Cuscuta haustorium during the infection process, will be essential to understanding the basis of the Cuscuta-host interaction and may thus advance knowledge about plant-plant dialogs in general. From this foundation, new perspectives for controlling parasitic pests may evolve.

\section{ACKNOWLEDGMENTS}

This work was supported by the Deutsche Forschungsgemeinschaft (DFG, AL 1426/1-1). We thank Hans Fürst for photography, and Georg Felix and Isabell Albert for their critical reading of the manuscript.

\section{SUPPLEMENTARY MATERIAL}

The Supplementary Material for this article can be found online at: http://www.frontiersin.org/journal/10.3389/fpls.2015.00045/ abstract

\section{REFERENCES}

Alakonya, A., Kumar, R., Koenig, D., Kimura, S., Townsley, B., Runo, S., et al. (2012). Interspecific RNA interference of SHOOT MERISTEMLESS-like disrupts Cuscuta pentagona plant parasitism. Plant Cell 24, 3153-3166. doi: 10.1105/tpc.112.099994

Albert, M. (2005). Studien zur Interaktion des Pflanzlichen Parasiten Cuscuta Reflexa mit dem Inkompatiblen Wirt Lycopersicum Esculentum. Ph.D. thesis, Technische Universität Darmstadt, Darmstadt. Available at: http://tuprints.ulb.tu-darmstadt.de/id/eprint/629

Albert, M., Belastegui-Macadam, X., Bleischwitz, M., and Kaldenhoff, R. (2008). Cuscuta spp: parasitic plants in the spotlight of plant physiology, economy, and ecology. Prog. Bot. 69, 267-277. doi: 10.1007/978-3-540-72954-9_11

Albert, M., Belastegui-Macadam, X., and Kaldenhoff, R. (2006). An attack of the plant parasite Cuscuta reflexa induces the expression of attAGP, an attachment protein of the host tomato. Plant J. 48, 548-556. doi: 10.1111/j.1365313X.2006.02897.x

Albert, M., Kaiser, B., Van Der Krol, S., and Kaldenhoff, R. (2010a). Calcium signaling during the plant-plant interaction of parasitic Cuscuta reflexa with its hosts. Plant Signal. Behav. 5, 1144-1146. doi: 10.4161/psb.5.9.12675

Albert, M., Van Der Krol, S., and Kaldenhoff, R. (2010b). Cuscuta reflexa invasion induces Ca2+ release in its host. Plant Biol. 12, 554-557. doi: 10.1111/j.14388677.2010.00322.x

Albert, M., Werner, M., Proksch, P., Fry, S. C., and Kaldenhoff, R. (2004). The cell wall-modifying xyloglucan endotransglycosylase/hydrolase LeXTH1 is expressed during the defence reaction of tomato against the plant parasite Cuscuta reflexa. Plant Biol. 6, 402-407. doi: 10.1055/s-2004-817959

Bartels, S., Lori, M., Mbengue, M., Van Verk, M., Klauser, D., Hander, T., et al. (2013). The family of Peps and their precursors in Arabidopsis: differential expression and localization but similar induction of pattern-triggered immune responses. J. Exp. Bot. 64, 5309-5321. doi: 10.1093/jxb/ert330

Bernards, M. A. (2002). Demystifying suberin. Can. J. Bot. Revue Can. de Bot. 80, 227-240. doi: 10.1139/b02-017

Birschwilks, M., Haupt, S., Hofius, D., and Neumann, S. (2006). Transfer of phloemmobile substances from the host plants to the holoparasite Cuscuta sp. J. Exp. Bot. 57, 911-921. doi: 10.1093/jxb/erj076

Bleischwitz, M., Albert, M., Fuchsbauer, H. L., and Kaldenhoff, R. (2010). Significance of Cuscutain, a cysteine protease from Cuscuta reflexa, in hostparasite interactions. BMC Plant Biol. 10:227. doi: 10.1186/1471-222910-227

Böhm, H., Albert, I., Fan, L., Reinhard, A., and Nurnberger, T. (2014). Immune receptor complexes at the plant cell surface. Curr. Opin. Plant Biol. 20C, 47-54. doi: 10.1016/j.pbi.2014.04.007

Boller, T., and Felix, G. (2009). A renaissance of elicitors: perception of microbe-associated molecular patterns and danger signals by pattern-recognition receptors. Annu. Rev. Plant Biol. 60, 379-406. doi: 10.1146/annurev.arplant.57.032905.105346

Capderon, M., Fer, A., and Ozenda, P. (1985). About an unreported system leading to the expulsion of a parasite - Cuscuta on cotton-plant (Cuscuta-Lupuliformis Krock on Gossypium-Hirsutum-L). C. R. Acad. Sci. III-Vie300, 227-232.

Chang, M., and Lynn, D. G. (1986). The haustorium and the chemistry of host recognition in parasitic angiosperms. J. Chem. Ecol. 12, 561-579. doi: 10.1007/BF01020572

Choi, J., Tanaka, K., Cao, Y., Qi, Y., Qiu, J., Liang, Y., et al. (2014). Identification of a plant receptor for extracellular ATP. Science 343, 290-294. doi: 10.1126/science.343.6168.290 
Cudney, D., and Lanini, W. T. (2000). Dodder. Encyclopedia Plant Pathol. 1, 376-379.

David-Schwartz, R., Runo, S., Townsley, B., Machuka, J., and Sinha, N. (2008). Longdistance transport of mRNA via parenchyma cells and phloem across the hostparasite junction in Cuscuta. New Phytol. 179, 1133-1141. doi: 10.1111/j.14698137.2008.02540.x

Dawson, J. H., Musselman, L. J., Wolswinkel, P., and Dörr, I. (1994). Biology and control of Cuscuta, Musselman, Rev. Weed Sci. 6, 265-317.

De Wit, P. J. G. M., Joosten, M. H. A. J., Thomma, B. P. H. J., and Stergiopoulos, I. (2009). Gene for gene models and beyond: the Cladosporium fulvum-tomato pathosystem. Mycota V Plant Relat. 5, 135-156. doi: 10.1007/9783-540-87407-2_7

Dodds, P. N., and Rathjen, J. P. (2010). Plant immunity: towards an integrated view of plant-pathogen interactions. Nat. Rev. Genet. 11, 539-548. doi: $10.1038 / \mathrm{nrg} 2812$

Dong, X. (1998). SA, LA, ethylene, and disease resistance in plants. Curr. Opin. Plant Biol. 1, 316-323. doi: 10.1016/1369-5266(88)80053-0

Dörr, I. (1968). Localization of cellcontacts between Cuscuta odorata and different higher hostplants. Protoplasma 65, 435-448.

Dörr, I. (1969). Fine structure of intracellular growing Cuscuta-Hyphae. Protoplasma $67,123-137$.

Dörr, I. (1972). Contact of Cuscuta-Hyphae with sieve tubes of Its host plants. Protoplasma 75, 167-187.

Durrant, W. E., and Dong, X. (2004). Systemic acquired resistance. Annu. Rev. Phytopathol. 42, 185-209. doi: 10.1146/annurev.phyto.42.040803.140421

Flor, H. H. (1956). Mutations in flax rust induced by Ultraviolet Radiation. Science 124, 888-889. doi: 10.1126/science.124.3227.888

Flor, H. H. (1971). Current status of the gene-for-gene concept. Annu. Rev. Phytopathol. 9, 275-296. doi: 10.1146/annurev.py.09.090171.001423

Funk, H. T., Berg, S., Krupinska, K., Maier, U. G., and Krause, K. (2007). Complete DNA sequences of the plastid genomes of two parasitic flowering plant species, Cuscuta reflexa and Cuscuta gronovii. BMC Plant Biol 7:45. doi: 10.1186/14712229-7-45

Garcia, M. A., Costea, M., Kuzmina, M., and Stefanovic, S. (2014). Phylogeny, character evolution, and biogeography of Cuscuta (dodders; Convolvulaceae) inferred from coding plastid and nuclear sequences. Am. J. Bot. 101, 670-690. doi: 10.3732/ajb.1300449

Goldwasser, Y. (2001). Tolerance of tomato varieties to lespedeza dodder. Weed Sci. 49, 520-523. doi: 10.1614/0043-1745(2001)049[0520:TOTVTL]2.0.CO;2

Goldwasser, Y., Miryamchik, H., Sibony, M., and Rubin, B. (2012). Detection of resistant chickpea (Cicer arietinum) genotypes to Cuscuta campestris (field dodder). Weed Res. 52, 122-130. doi: 10.1111/j.1365-3180.2012.00904.x

Goldwasser, Y., Plakhine, D., Kleifeld, Y., Zamski, E., and Rubin, B. (2000). The differential susceptibility of vetch (Vicia spp.) to Orobanche aegyptiaca: anatomical studies. Ann. Bot. 85, 257-262. doi: 10.1006/anbo.1999.1029

Haupt, S., Oparka, K. J., Sauer, N., and Neumann, S. (2001). Macromolecular trafficking between Nicotiana tabacum and the holoparasite Cuscuta reflexa. J. Exp. Bot. 52, 173-177. doi: $10.1093 /$ jexbot/52.354.173

Heidejorgensen, H. S. (1991). Anatomy and ultrastructure of the haustorium of Cassytha-Pubescens R Br I the adhesive Disk. Bot. Gazette 152, 321-334. doi: $10.1086 / 337896$

Hibberd, J. M., Bungard, R. A., Press, M. C., Jeschke, W. D., Scholes, J. D., and Quick, W. P. (1998). Localization of photosynthetic metabolism in the parasitic angiosperm Cuscuta reflexa. Planta 205, 506-513. doi: 10.1007/s0042500 50349

Hibberd, J. M., and Jeschke, W. D. (2001). Solute flux into parasitic plants. J. Exp. Bot. 52, 2043-2049. doi: 10.1093/jexbot/52.363.2043

Hibberd, J. M., Quick, W. P., Press, M. C., Scholes, J. D., and Jeschke, W. D. (1999), Solute fluxes from tobacco to the parasitic angiosperm Orobanche cernua and the influence of infection on host carbon and nitrogen relations. Plant Cell Environ. 22, 937-947. doi: 10.1046/j.1365-3040.1999.00462.x

Ihl, B., Tutakhil, N., Hagen, A., and Jacob, F. (1988). Studies on Cuscuta Reflexa Roxb.7. Defense-mechanisms of Lycopersicon esculentum Mill. Flora 181, 383-393.

Jeschke, W. D., Baig, A., and Hilpert, A. (1997). Sink-stimulated photosynthesis, increased transpiration and increased demand-dependent stimulation of nitrate uptake: nitrogen and carbon relations in the parasitic association Cuscuta reflexa Coleus blumei. J. Exp. Bot. 48, 915-925. doi: 10.1093/jxb/48. 4.915
Jeschke, W. D., Baumel, P., Rath, N., Czygan, F. C., and Proksch, P. (1994). Modeling of the flows and partitioning of carbon and nitrogen in the holoparasite Cuscuta reflexa Roxb and its host Lupinus albus 1.2. Flows between host and parasite and within the parasitized host. J. Exp. Bot. 45, 801-812. doi: 10.1093/jxb/45.6.801

Jiang, L., Qu, F., Li, Z., and Doohan, D. (2013a). Inter-species protein trafficking endows dodder (Cuscuta pentagona) with a host-specific herbicide-tolerant trait. New Phytol. 198, 1017-1022. doi: 10.1111/nph.12269

Jiang, L. J., Wijeratnen, A. J., Wijeratne, S., Frage, M., Meulia, T., Doohan, D., et al. (2013b). Profiling mRNAs of two Cuscuta species reveals possible candidate transcripts shared by parasitic plants. PLoS ONE 8:e81389. doi: 10.1371/journal.pone. 0081389

Joosten, M. H. A. J., Cozijnsen, T. J., and De Wit, P. J. G. M. (1994). Host resistance to a fungal tomato pathogen lost by a single base-pair change in an avirulence gene. Nature 367, 384-386. doi: 10.1038/367384a0

Kim, G., Leblanc, M. L., Wafula, E. K., Depamphilis, C. W., and Westwood, J. H. (2014). Plant science. Genomic-scale exchange of mRNA between a parasitic plant and its hosts. Science 345, 808-811. doi: 10.1126/science.1253122

Küfner, I., Ottmann, C., Oecking, C., and Nurnberger, T. (2009). Cytolytic toxins as triggers of plant immune response. Plant Signal. Behav. 4, 977-979. doi: 10.4161/psb.4.10.9669

Kuijt, J. (1969). The Biology of Parasitic Flowering Plants. Berkeley, CA: University California Press. 246, 1081-1082.

Lanfermeijer, F. C., Dijkhuis, J., Sturre, M. J., De Haan, P., and Hille, J. (2003). Cloning and characterization of the durable tomato mosaic virus resistance gene Tm-2(2) from Lycopersicon esculentum. Plant Mol. Biol. 52, 1037-1049. doi: 10.1023/A:1025434519282

Lanini, W., and Kogan, M. (2005). Biology and management of Cuscuta in crops. Cien. Inv. Agr. 32, 165-179.

Leide, J., Hildebrandt, U., Hartung, W., Riederer, M., and Vogg, G. (2012). Abscisic acid mediates the formation of a suberized stem scar tissue in tomato fruits. New Phytol. 194, 402-415. doi: 10.1111/j.1469-8137.2011. 04047.x

Li, J., Lis, K. E., and Timko, M. P. (2009). Molecular genetics of race-specific resistance of cowpea to Striga gesnerioides (Willd.). Pest. Manag. Sci. 65, 520-527. doi: $10.1002 /$ ps.1722

Li, J., and Timko, M. P. (2009). Gene-for-gene resistance in Striga-cowpea associations. Science 325, 1094. doi: 10.1126/science.1174754

Löffler, C., Czygan, F. C., and Proksch, P. (1997). Phenolic constituents as taxonomic markers in the genus Cuscuta (Cuscutaceae). Biochem. Syst. Ecol. 25, 297-303. doi: 10.1016/S0305-1978(97)00015-X

Löffler, C., Czygan, F. C., and Proksch, P. (1999). Role of indole-3-acetic acid in the interaction of the phanerogamic parasite Cuscuta and host plants. Plant Biol. 1, 613-617. doi: 10.1111/j.1438-8677.1999.tb00271.x

Löffler, C., Sahm, A., Wray, V., Czygan, F. C., and Proksch, P. (1995). Soluble phenolic constituents from Cuscuta-Reflexa and Cuscuta-Platyloba. Biochem. Syst. Ecol. 23, 121-128. doi: 10.1016/0305-1978(95)93846-U

Mabberley, O. J. (1997). The Plant Book: A Portable Dictionary of the Vascular Plants. 2nd edn. Cambridge: Cambridge University Press.

Macho, A. P., and Zipfel, C. (2014). Plant PRRs and the activation of innate immune signaling. Mol. Cell. 54, 263-272. doi: 10.1016/j.molcel.2014.03.028

McNeal, J. R., Arumugunathan, K., Kuehl, J. V., Boore, J. L., and Depamphilis, C. W. (2007a). Systematics and plastid genome evolution of the cryptically photosynthetic parasitic plant genus Cuscuta (Convolvulaceae). BMC Biol. 5:55. doi: 10.1186/1741-7007-5-55

McNeal, J. R., Kuehl, J. V., Boore, J. L., and De Pamphilis, C. W. (2007b). Complete plastid genome sequences suggest strong selection for retention of photosynthetic genes in the parasitic plant genus Cuscuta. BMC Plant Biol 7:57. doi: $10.1186 / 1471-2229-7-57$

Mescher, M. C., Runyon, J. B., and De Moraes, C. M. (2006). Plant host finding by parasitic plants: a new perspective on plant to plant communication. Plant Signal. Behav. 1, 284-286. doi: 10.4161/psb.1.6.3562

Nadler-Hassar, T., and Rubin, B. (2003). Natural tolerance of Cuscuta campestris to herbicides inhibiting amino acid biosynthesis. Weed Res. 43, 341-347. doi: 10.1046/j.1365-3180.2003.00350.x

Ottmann, C., Rose, R., Huttenlocher, F., Cedzich, A., Hauske, P., Kaiser, M., et al. (2009). Structural basis for Ca2+-independence and activation by homodimerization of tomato subtilase 3. Proc. Natl. Acad. Sci. U.S.A. 106, 17223-17228. doi: 10.1073/pnas.0907587106 
Parker, C. (1991). Protection of crops against parasitic weeds. Crop Protect. 10, 6-22. doi: 10.1016/0261-2194(91)90019-N

Perez-de-Luque, A., Lozano, M. D., Cubero, J. I., Gonzalez-Melendi, P., Risueno, M. C., and Rubiales, D. (2006). Mucilage production during the incompatible interaction between Orobanche crenata and Vicia sativa. J. Exp. Bot. 57, 931-942. doi: 10.1093/jxb/erj078

Perez-de-Luque, A., Moreno, M. T., and Rubiales, D. (2008). Host plant resistance against broomrapes (Orobanche spp.): defence reactions and mechanisms of resistance. Ann. Appl. Biol. 152, 131-141. doi: 10.1111/j.1744-7348.2007. 00212.x

Ranjan, A., Ichihashi, Y., Farhi, M., Zumstein, K., Townsley, B., DavidSchwartz, R., et al. (2014). De novo assembly and characterization of the transcriptome of the parasitic weed Cuscuta pentagona identifies genes associated with plant parasitism. Plant Physiol. 166, 1186-1199. doi: 10.1104/pp.113. 234864

Rejmanek, M. A., and Pitcairn, M. J. (2002). "When is eradication of exotic pest plants a realistic goal?," in Turning the Tide: The Eradication of Invasive Species, eds C. R. Veitch and M. N. Clout (Gland: IUCN SSC Invasive Species Specialist Group), 249-253.

Roney, J. K., Khatibi, P. A., and Westwood, J. H. (2007). Cross-species translocation of mRNA from host plants into the parasitic plant dodder. Plant Physiol. 143, 1037-1043. doi: 10.1104/pp.106.088369

Rubiales, D., Perez-de-Luque, A., Joel, D. M., Alcantara, C., and Sillero, J. C. (2003). Characterization of resistance in chickpea to crenate broomrape (Orobanche crenata). Weed Sci. 51, 702-707. doi: 10.1614/P2002-151

Runo, S., Alakonya, A., Machuka, J., and Sinha, N. (2011). RNA interference as a resistance mechanism against crop parasites in Africa: a 'Trojan horse' approach Pest. Manag. Sci. 67, 129-136. doi: 10.1002/Ps.2052

Runo, S., Macharia, S., Alakonya, A., Machuka, J., Sinha, N., and Scholes, J. (2012) Striga parasitizes transgenic hairy roots of Zea mays and provides a tool for studying plant-plant interactions. Plant Methods 8, 20. doi: 10.1186/1746-4811$8-20$

Runyon, J. B., Mescher, M. C., and De Moraes, C. M. (2006). Volatile chemical cues guide host location and host selection by parasitic plants. Science 313, 1964-1967. doi: $10.1126 /$ science.1131371

Runyon, J. B., Mescher, M. C., Felton, G. W., and De Moraes, C. M. (2010). Parasitism by Cuscuta pentagona sequentially induces JA and SA defence pathways in tomato. Plant Cell Environ. 33, 290-303. doi: 10.1111/j.1365-3040.2009. 02082.x

Sahm, A., Pfanz, H., Grunsfelder, M., Czygan, F. C., and Proksch, P. (1995). Anatomy and phenylpropanoid metabolism in the incompatible interaction of Lycopersicon-Esculentum and Cuscuta-Reflexa. Botanica Acta 108, 358-364. doi: 10.1111/j.1438-8677.1995.tb00506.x

Sakimura, K. (1947). Virus Transmission by Cuscuta-Sandwichiana. Phytopathology $37,66-67$.

Spallek, T., Mutuku, M., and Shirasu, K. (2013). The genus Striga: a witch profile. Mol. Plant Pathol. 14, 861-869. doi: 10.1111/mpp.12058

Srivastava, S., Nighojkar, A., and Kumar, A. (1994). Multiple forms of pectin methylesterase from Cuscuta-Reflexa Filaments. Phytochemistry 37, 1233-1236. doi: 10.1016/S0031-9422(00)90390-X
Stefanovic, S., Kuzmina, M., and Costea, M. (2007). Delimitation of major lineages within Cuscuta subgenus Grammica (convolvulaceae) using plastid and nuclear DNA sequences. Am. J. Bot. 94, 568-589. doi: 10.3732/Ajb.94.4.568

Vaughn, K. C. (2002). Attachment of the parasitic weed dodder to the host. Protoplasma 219, 227-237. doi: 10.1007/s007090200024

Vaughn, K. C. (2003). Dodder hyphae invade the host: a structural and immunocytochemical characterization. Protoplasma 220, 189-200. doi: 10.1007/s00709002-0038-3

Wasternack, C., Stenzel, I., Hause, B., Hause, G., Kutter, C., Maucher, H., et al. (2006). The wound response in tomato-role of jasmonic acid. J. Plant Physiol. 163, 297-306. doi: 10.1016/j.jplph.2005.10.014

Werner, M., Uehlein, N., Proksch, P., and Kaldenhoff, R. (2001). Characterization of two tomato aquaporins and expression during the incompatible interaction of tomato with the plant parasite Cuscuta reflexa. Planta 213, 550-555. doi: $10.1007 / \mathrm{s} 004250100533$

Westwood, J. H., Roney, J. K., Khatibi, P. A., and Stromberg, V. K. (2009). RNA translocation between parasitic plants and their hosts. Pest. Manag. Sci. 65, 533539. doi: $10.1002 /$ ps. 1727

Westwood, J. H., Yoder, J. I., Timko, M. P., and Depamphilis, C. W. (2010). The evolution of parasitism in plants. Trends Plant Sci. 15, 227-235. doi: 10.1016/j.tplants.2010.01.004

Wulff, B. B., Chakrabarti, A., and Jones, D. A. (2009). Recognitional specificity and evolution in the tomato-Cladosporium fulvum pathosystem. Mol. Plant Microbe Interact. 22, 1191-1202. doi: 10.1094/MPMI-22-10-1191

Yoder, J. I., and Scholes, J. D. (2010). Host plant resistance to parasitic weeds; recent progress and bottlenecks. Curr. Opin. Plant Biol. 13, 478-484. doi: 10.1016/j.pbi.2010.04.011

Yoshida, S., and Shirasu, K. (2009). Multiple layers of incompatibility to the parasitic witchweed, Striga hermonthica. New Phytol. 183, 180-189. doi: 10.1111/j.14698137.2009.02840.x

Yuncker, T. G. (1932). The genus Cuscuta. Memoirs Torrey Botanical Club 18,109-331.

Conflict of Interest Statement: The authors declare that the research was conducted in the absence of any commercial or financial relationships that could be construed as a potential conflict of interest.

Received: 15 September 2014; accepted: 16 January 2015; published online: 04 February 2015.

Citation: Kaiser B, Vogg G, Fürst UB and Albert M (2015) Parasitic plants of the genus Cuscuta and their interaction with susceptible and resistant host plants. Front. Plant Sci. 6:45. doi: 10.3389/fpls.2015.00045

This article was submitted to Plant-Microbe Interaction, a section of the journal Frontiers in Plant Science.

Copyright (0) 2015 Kaiser, Vogg, Fürst and Albert. This is an open-access article distributed under the terms of the Creative Commons Attribution License (CC BY). The use, distribution or reproduction in other forums is permitted, provided the original author(s) or licensor are credited and that the original publication in this journal is cited, in accordance with accepted academic practice. No use, distribution or reproduction is permitted which does not comply with these terms. 